\title{
First report of the Citrus tristeza virus resistance-breaking strain in Morocco
}

\author{
Mohamed Afechtal ${ }^{1,2,3} \cdot$ Anna Maria D'Onghia $^{3} \cdot$ Giuseppe Eros Massimino Cocuzza $^{2} \cdot$ Khaled Djelouah $^{3}$
}

Received: 2 February 2018 / Accepted: 20 April 2018 / Published online: 8 May 2018

(C) Società Italiana di Patologia Vegetale (S.I.Pa.V.) 2018

Citrus tristeza virus (CTV), a member of the genus Closterovirus, causes the most destructive virus disease of citrus in the world. During 2008, an important outbreak of CTV was detected in the Loukkos region in Northwestern Morocco (Afechtal et al. 2011). One CTV isolate recovered from a 'common' clementine tree in this region was collected for characterization studies. Total nucleic acids were extracted from leaves with RNeasy Plant Mini Kit (Qiagen, Germany) and analyzed by reverse transcription polymerase chain reaction (RT-PCR) using specific primers to amplify the coat protein (CP) gene (Hilf and Garnsey 2000). The RT-PCR products were cloned into the pUC18 plasmid vector (Agilent Technologies, USA), then five clones were sequenced. All of them were nearly identical; consequently only one was deposited in GenBank under the accession number HF947330. Nucleotide sequence analysis indicated 98.8\% identity to Poncirus trifoliata resistance-breaking (RB) isolate B301 from Puerto Rico (JF957196), and 97\% to RB isolate NZRB-90 from New Zealand (FJ525432; Harper et al. 2010). The RB phenotype was confirmed by RT-PCR detecting CTV replication in graft-inoculated $P$. trifoliata, and graft transmission from P. trifoliata to sweet orange. CP gene amplicons were amplified from the graft-inoculated P. trifoliata and the relative sequences showed highest nucleotide identity with the $\mathrm{RB}$ strain. To the best of our knowledge, this is the first report of CTV P. trifoliata RB strain in Morocco. It is important to highlight that all CTV-infected trees in the Loukkos region have been completely eradicated by the national plant protection organization.

\section{References}

Afechtal M, Djelouah K, D'Onghia AM (2011) Detection of an outbreak of Citrus tristeza virus in Morocco. Integr Control Citrus Fruit Crops IOBC/wprs Bull 62:12

Harper SJ, Dawson TE, Pearson MN (2010) Isolates of Citrus tristeza virus that overcome Poncirus trifoliata resistance comprise a novel strain. Arch Virol 155:471-480

Hilf ME, Garnsey S M (2000) Characterization and classification of Citrus tristeza virus isolates by amplification of multiple molecular markers. In: da Graça J. V., Lee R. F., Yokomi R. (ed.). Proceedings of the $14^{\text {th }}$ Conference of the International Organization of Citrus Virologists, Brazil, 1998, pp 18-27
Mohamed Afechtal

mohamedafechtal.inra@gmail.com

1 Regional Agricultural Research Center of Kénitra, Laboratory of Virology, National Institute for Agricultural Research (INRA), 14 rue Abou Temmam, B.P. 257, Kénitra, Morocco

2 Dipartimento di di Agricoltura, Alimentazione e Ambiente, sez. Entomologia, Università degli Studi di Catania, via Santa Sofia, 100, Catania, Italy

3 Centre International de Hautes Etudes Agronomiques Méditerranéenes, Itituto Agronomico Mediterraneo di Bari (CIHEAM/MAIB), Via Ceglie 9, 70010 Valenzano, BA, Italy 